University of Wollongong

Research Online

Australian Institute for Innovative Materials -

Papers

Australian Institute for Innovative Materials

$1-3-2018$

In operando mechanism analysis on nanocrystalline silicon anode material for reversible and ultrafast sodium storage

\author{
Lei Zhang \\ University of Wollongong, Iz755@uowmail.edu.au \\ Xianluo $\mathrm{Hu}$ \\ Huazhong University of Science and Technology \\ Chaoji Chen \\ Huazhong University of Science and Technology \\ Haipeng Guo \\ University of Wollongong, hg476@uowmail.edu.au \\ Xiaoxiao Liu \\ Huazhong University of Science and Technology
}

See next page for additional authors

Follow this and additional works at: https://ro.uow.edu.au/aiimpapers

Part of the Engineering Commons, and the Physical Sciences and Mathematics Commons

Research Online is the open access institutional repository for the University of Wollongong. For further information contact the UOW Library: research-pubs@uow.edu.au 


\title{
In operando mechanism analysis on nanocrystalline silicon anode material for reversible and ultrafast sodium storage
}

\begin{abstract}
Presently, lithium-ion batteries (LIBs) are the most promising commercialized electrochemical energy storage systems. Unfortunately, the limited resource of Li results in increasing cost for its scalable application and a general consciousness of the need to find new type of energy storage technologies. Very recently, substantial effort has been invested to sodium-ion batteries (SIBs) due to their effectively unlimited nature of sodium resources. Furthermore, the potential of $\mathrm{Li} / \mathrm{Li}+$ is $0.3 \mathrm{~V}$ lower than that of $\mathrm{Na}$ / $\mathrm{Na}+$, which makes it more effective to limit the electrolyte degradation on the outer surface of the electrode.[1] Nevertheless, one major obstacle for the commercial application of SIBs is the larger ionic radius of $\mathrm{Na}+(0.98 \AA)$ which is $0.29 \AA$ larger than that of $\mathrm{Li}+$, resulting in easier structural degradation for the $\mathrm{Na}+$ host materials.[2,3] As anode materials for SIBs, the traditional carbon-based materials like hard carbon[4] and porous carbon,[5,6] tin (Sn),[7] and antimony (Sb)[8] show poor cycle performance due to their large volume expansion caused by $\mathrm{Na}$ insertion.
\end{abstract}

\section{Keywords}

nanocrystalline, storage, silicon, anode, material, sodium, mechanism, reversible, ultrafast, analysis, operando

Disciplines

Engineering | Physical Sciences and Mathematics

\section{Publication Details}

Zhang, L., Hu, X., Chen, C., Guo, H., Liu, X., Xu, G., Zhong, H., Cheng, S., Wu, P., Meng, J., Huang, Y., Dou, S. \& Liu, H. (2017). In operando mechanism analysis on nanocrystalline silicon anode material for reversible and ultrafast sodium storage. Advanced Materials, 29 1604708-1-1604708-8.

\section{Authors}

Lei Zhang, Xianluo Hu, Chaoji Chen, Haipeng Guo, Xiaoxiao Liu, Gengzhao Xu, Haijian Zhong, Shuang

Cheng, Peng Wu, Jiashen Meng, Yunhui Huang, Shi Xue Dou, and Hua-Kun Liu 
DOI: 10.1002/adma.((please add manuscript number))

Submitted to

Article type: Communication

In-operando mechanism analysis on nanocrystalline silicon anode material for reversible and ultra-fast sodium storage

Lei Zhang, Xianluo Hu, * Chaoji Chen, Haipeng Guo, Xiaoxiao Liu, Gengzhao Xu, Haijian Zhong, Shuang Cheng, Peng Wu, Jiashen Meng, Yunhui Huang, * Shixue Dou, Huakun Liu*

Lei Zhang, Haipeng Guo, Prof. Shixue Dou, Prof. Huakun Liu,

Institute for Superconducting and Electronic Materials

University of Wollongong

Squires Way, North Wollongong, NSW 2500, Australia

Email: hua@uow.edu.au

Prof. Xianluo Hu, Dr. Chaoji Chen, Xiaoxiao Liu, Prof Yunhui Huang

State Key Laboratory of Materials Processing and Die \& Mould Technology

School of Materials Science and Engineering

Huazhong University of Science and Technology, Wuhan 430074, P.R. China.

Email: huxl@mail.hust.edu.cn, huangyh@hust.edu.cn

Dr. Gengzhao Xu, Dr. Haijian Zhong

Suzhou Institute of Nano-Tech and Nano-Bionics

Chinese Academy of Sciences

Suzhou, Jiangsu 215123, P. R. China.

Prof. Shuang Cheng, Peng Wu

New Energy Research Institute

School of Environment and Energy

South China University of Technology

Guangzhou Higher Education Mega Center

Guangzhou, Guangdong 510006, P. R. China.

Jiashen Meng

State Key Laboratory of Advanced Technology for Materials Synthesis and Processing

Wuhan University of Technology

Wuhan, Hubei 430070, China.

Keywords: nanocrystal silicon, in-operando analysis, anode, sodium ion battery 

electrochemical energy storage systems. Unfortunately, the limited resource of Li results in increasing cost for its scalable application and a general consciousness of the need to find new type of energy storage technologies. Very recently, substantial effort has been invested to sodium-ion batteries (SIBs) due to their effectively unlimited nature of sodium resources. Furthermore, the potential of $\mathrm{Li} / \mathrm{Li}^{+}$is $0.3 \mathrm{~V}$ lower than that of $\mathrm{Na} / \mathrm{Na}^{+}$, which makes it more effective to limit the electrolyte degradation on the outer surface of the electrode. ${ }^{[1]}$ Nevertheless, one major obstacle for the commercial application of SIBs is the larger ionic radius of $\mathrm{Na}^{+}(0.98 \AA)$ which is $0.29 \AA$ larger than that of $\mathrm{Li}^{+}$, resulting in easier structural degradation for the $\mathrm{Na}^{+}$host materials. ${ }^{[2,3]}$ As anode materials for SIBs, the traditional carbonbased materials like hard carbon ${ }^{[4]}$ and porous carbon ${ }^{[5,6]}$, tin $(\mathrm{Sn})^{[7]}$ and antimony $(\mathrm{Sb})^{[8]}$ show poor cycle performance due to their large volume expansion caused by $\mathrm{Na}^{+}$insertion.

Compared with the commercial carbon-based anodes with a relatively low theoretical capacity (below $380 \mathrm{mAh} \mathrm{g}^{-1}$ ) in LIBs, silicon ( $\mathrm{Si}$ )-based materials are particularly promising because of their extremely high reversible specific capacity (3590 mAh g ${ }^{-1}$, corresponding to $\left.\mathrm{Li}_{15} \mathrm{Si}_{4}\right) \cdot{ }^{[9-13]}$ Very excitingly, many previous theoretical calculations have predicted that $\mathrm{Na}$ can also alloy with $\mathrm{Si}$ to form $\mathrm{NaSi}\left(\mathrm{Si}+\mathrm{Na}^{+}+\mathrm{e}^{-} \leftrightarrow \mathrm{NaSi}\right)$, providing a specific capacity around $960 \mathrm{mAh} \mathrm{g}^{-1} \cdot{ }^{[14,15]}$ Therefore, from the viewpoint of high energy density, Si-based anode material is also an excellent choice for SIBs. Unfortunately, realizing reversible $\mathrm{Na}^{+}$ insertion in crystalline $\mathrm{Si}(\mathrm{c}-\mathrm{Si})$ is still impeded by difficulties. Only one report on the charge/discharge-reversible Si anode for SIBs was published very recently, where nanosized Si contained a significant amount (more than 60\%) of amorphous $\mathrm{Si}$ (a-Si) as anodes in SIBs. ${ }^{[1]}$ Owing to the essential disadvantages of $\mathrm{Si}$ (e.g., the low conductivity and large volume change during cycling), however, poor rate performance and cycle life were unavoidable. Also, the sodiation mechanism has not been well elaborated so far. 


\section{Submitted to

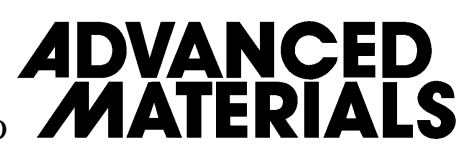

Herein, we demonstrate for the first time the feasibility of nanosized c-Si (below $100 \mathrm{~nm}$ in diameter) as the original anode in SIBs. Taking advantages of in-operando Raman spectroscopy that is also first reported for Si-based anodes, and kinetics analysis, we find that an irreversible crystal structure conversion occurs during the first $\mathrm{Na}^{+}$insertion/extraction processes, resulting in an irreversible decrease in the crystallinity within the initial c-Si. Ultrafast reversible reactions between the newly generated a-Si and $\mathrm{Na}^{+}$ions then proceeded smoothly during the subsequent cycles. In addition, the size effect of the starting c-Si nanocrystals also has a significant influence on the reversible $\mathrm{Na}^{+}$insertion/extraction into/from c-Si. Microsized c-Si showed a very low specific capacity and didn't show any structural conversion in terms of the electrochemical and in-operando X-ray diffraction (XRD) analyses, respectively. Unfortunately, the cyclability of the pure nanosized c-Si was poor, resulting in a rapid decay in capacity even during initial several cycles. This can be explained by the volume expansion/constriction during $\mathrm{Na}^{+}$insertion/extraction processes. ${ }^{[16]}$ As a result, structural degradation in the expanded c-Si quickly took place, and these destructive Si particles were subsequently dispersed into the electrolyte, leading to the poor structural stability. Another disadvantage of pure c-Si is the low conductivity, which is negative for rate performance. ${ }^{[10,11]}$

Based on our research on the sodiation mechanism of nanosized c-Si, herein, the electrochemical abilities of pure nanosized c-Si electrode could be improved via carbon doping and nanostructural design. Inspired by the previous work on Si-based anodes in LIBs ${ }^{[17-26]}$ loading Si nanoparticles (Si NPs) within one-dimensional (1D) carbon nanofibers is one of the most desirable strategies to improve the conductivity and rate capability. Such an attractive structure can provide shortened path for ionic diffusion and effective electron transfer in the radial direction. As for the volume expansion of c-Si, yolk-shell carbon/void/Si (CVS) composite is prospective, since the introduced gap provides space for Si NPs without wrecking the outer coatings and the solid electrolyte interphase (SEI) film. ${ }^{[11,27]}$ Therefore, by 


\section{Submitted to

integrating 1D carbon nanofibers and the yolk-shell structure, it is feasible to create highperformance Si anodes.

In this work, we fabricated a flexible binder-free bamboo-rattle type $\mathrm{Si} / \mathrm{C}$ film via a electrospinning technology. Typically, CVS nanobeads were first prepared through a templating method, whereby Si NPs were enwrapped with a uniform silica coating $\left(\mathrm{SiO}_{2} @ \mathrm{Si}\right)$, and then these $\mathrm{SiO}_{2} @ \mathrm{Si}$ nanospheres were uniformly distributed into the carbon nanofibers through a facile and scalable electrospinning method. After the treatment of carbonization and HF etching, the final Si/C composite with a well-defined yolk-shell nanoarchitecture was achieved. Very encouragingly, the resulting $\mathrm{Si} / \mathrm{C}$ hybrid is flexible, and exhibits high reversible capacity, ultrafast sodium storage and outstanding cyclability in SIBs.

Figure S1a shows the experimental and simulated XRD patterns of nanosized c-Si with Rietveld refinement. All the peaks are strongly correlated to c-Si, and no other peaks can be found. ${ }^{[12]}$ The refinement with a space group of cubic $F d-3 m$ (227) gives the lattice parameters of $a=b=c=5.4271(1) \AA$ and $V=159.85(0) \AA^{3}$ with reasonably low $R$-factors $(6.35 \%)$ and $x^{2}(0.9358)$ value using the GSAS suite. ${ }^{[29]}$ Figure S1b shows the schematics of the cubic structure of nanosized c-Si. Figure S1c presents the scanning electron microscopy (SEM) image of the slightly agglomerated nanosized c-Si NPs with a diemeter of 80-100 nm. Figure S1d reveals the SEM picture of microsized c-Si with an irregular morphology in the size range of about $2-5 \mu \mathrm{m}$. Figure S1e illustrates the high-resolution transmission electron microscopy (HRTEM) image and its corresponding fast Fourier transformation (FFT) pattern of an individual nanosized c-Si particle, which shows the resolved Si lattice planes with a plane distance of about $0.16 \mathrm{~nm}$, consistent with the Si crystal's (400) planes. ${ }^{[13]}$

Figure 1a shows the 1st, 2nd, 50th, 100th and 200th charge and discharge curves of pure nanosized c-Si at a current density of $50 \mathrm{~mA} \mathrm{~g}^{-1}$. The discharge and charge capacities in the first cycle are 869.6 and $170.8 \mathrm{mAh} \mathrm{g}^{-1}$ (corresponding to $\mathrm{Na} 0.91 \mathrm{Si}$ ), and there is considerable capacity decrease in the next cycles. Although the pure nanosized c-Si exhibits poor cycling 
extraction reactions happen in the pure stability, it is obvious that reversible $\mathrm{Na}^{+}$insertion/extraction reactions happen in the pure nanosized c-Si electrode based on these discharge-charge profiles and the inset cyclic voltammetry $(\mathrm{CV})$ data. During the first discharge, a sloping voltage plateau at $0.75 \mathrm{~V}$ can be found. However, the plateau becomes less and less obvious in the following cycles. This can be further confirmed by the reduction peaks at about $0.75 \mathrm{~V}$ (which follow the same changes in intensity as the platforms at $0.75 \mathrm{~V}$ in Figure 1a) in the $\mathrm{CV}$ profiles (inset of Figure 1a), indicating the continual reformation of the SEI layers as a result of the repeated pulverization of nanosized $\mathrm{c}-\mathrm{Si}^{\left[{ }^{[16]}\right.}$ Another voltage plateau below $0.5 \mathrm{~V}$ in the discharge profile is consistent with the reduction peak at $0.2 \mathrm{~V}$ in the $\mathrm{CV}$ plot, which is related to the $\mathrm{Na}$ ion uptake and alloying process with $\mathrm{c}-\mathrm{Si}^{[1]}$ In addition, the intensity of these reductive peaks around $0.2 \mathrm{~V}$ decrease gradually upon cycling, indicating the weaker and weaker active reactions between active $\mathrm{c}-\mathrm{Si}$ and $\mathrm{Na}$ ions in the electrode. This can be explained by the reduced amount of active $\mathrm{c}-\mathrm{Si}$, arising from continuous pulverization and volume expansion of nanosized c-Si during discharge/charge cycles. ${ }^{[16]}$ Compared with the initial discharge profile with obvious long plateaus around $0.5 \mathrm{~V}$, however, no flat plateaus can be found in the following discharge cycles. Therefore, different reaction mechanisms may occur during the $\mathrm{Na}^{+}$insertion in the initial and subsequent discharge processes, respectively. The galvanostatic discharge/charge profiles and the $\mathrm{CV}$ curves suggest that the initial $\mathrm{Na}^{+}$ insertion process is more like the typical alloying reaction behavior, while the following ones tend to show the capacitive behavior (Figure S2). ${ }^{[28]}$ Moreover, the platforms below $0.75 \mathrm{~V}$ in the charge profiles correspond to the broad oxidative peaks between $0.01-0.75 \mathrm{~V}$ in the $\mathrm{CV}$ curves (inset of Figure 1a). Evidently, these curves could not be well overlaped, indicating the poor structural and cycling stability of nanosized c-Si for sodium storage.

Based on $\mathrm{CV}$ results, kinetic analyses have been carried out to further understand the electrochemistry of the nanosized c-Si/Na cell. Figure S2a shows the CV profiles with broad 


\section{Submitted to

peaks at different scan rates from $0.1-20 \mathrm{mV} \mathrm{s}^{-1}$ during both charge and discharge processes.

Based on the relationship between current $(i)$ and the scan rate $(v)^{[29]}$ :

$i=\mathrm{a} v^{b}$

the $b$-value is obtained from the slope of the $\log (v)-\log (i)$ plots. Particularly, the $b$-value of 0.5 demonstrates an $100 \%$ diffusion-controlled process, while 1.0 indicates a capacitive behavior. Figure $\mathrm{S} 2 \mathrm{~b}$ shows the $\log (v)-\log (i)$ result for the nanosized $\mathrm{c}-\mathrm{Si}$ electrode. The $b$ value is 0.79 for the oxidation peaks at scan rates between $0.2-20 \mathrm{mV} \mathrm{s}^{-1}$, indicative of the kinetics of capacitance-dominated performance. The total capacitive contribution can be quantified by distinguishing the different contribution from the diffusion or capacitancecontrolled charge at a certain voltage under a fixed scan rate. Figure S2c shows that the diffusion-controlled charge mostly took place around the peak voltage, suggesting that the diffusion-controlled process is available in this area and consistent with an alloying interaction behavior between $\mathrm{Si}$ and $\mathrm{Na}$ ions. ${ }^{[30]}$ Depend on the quantification, $68 \%$ of the total charge is capacitive at a scan rate of $10 \mathrm{mV} \mathrm{s}^{-1}$. Contribution ratios between these two different processes at other different scan rates were also tested. The capacitive capacity grows progressively with rising the scan rate, and reaches a maximum value of $68 \%$ at 10 $\mathrm{mV} \mathrm{s}^{-1}$ finally (Figure S2d).

The $\mathrm{Na}^{+}$storage capability of the microsized c-Si anode was also explored by in-operando XRD patterns (Figure 1b). There is no change in the intensity of the Si peak around $29.7^{\circ}$. This suggests that no structural conversions or reversible reactions could proceed in the microsized c-Si electrode, and the capacity of the microsized c-Si electrode is negligible (see Figure S3). Therefore, the electrochemical behavior of the c-Si strongly depends on the particle size. In another word, the surface area of the c-Si plays a very important role in its final electrochemical performance. The BET surface area of microsized c-Si and nanosized c$\mathrm{Si}$ is around 12 and $36 \mathrm{~m}^{2} \mathrm{~g}^{-1}$, respectively. The surface area of nanosized c-Si is three times 


\section{ADVANCEP}

Submited to MATERIALS

higher than that of the microsized c-Si. Therefore, compared with the microsized c-Si, reversible reactions with $\mathrm{Na}^{+}$ions are more available and accessible in the nanosized c-Si.

For better insight into the crystal structure change and the electrochemical activity of the nanosized c-Si during sodiation/extraction processes, in-operando Raman analyses during the electrochemical reactions were conducted. Figure 2a shows the in-operando Raman spectra for the pure nanosized c-Si electrode during the first $\mathrm{CV}$ cycle. The acquisition time for each Raman spectrum is $500 \mathrm{~s}$, and each Raman spectrum is consequently acquired within $0.2 \mathrm{~V}$. The potential output of the original half SIB is $1.8 \mathrm{~V}$, and the total measurement time for the first CV cycle is $12,000 \mathrm{~s}$. The peak located at about $520 \mathrm{~cm}^{-1}$ is attributed to c-Si, while the peaks at about $1350 \mathrm{~cm}^{-1}$ (D-band) and $1600 \mathrm{~cm}^{-1}$ (G-band) are ascribed to carbon. ${ }^{[11]}$ No other sharp peaks could be found from the charged/discharged electrode. The intensity of the Si peak in the Raman spectrum is directly related to its crystal structure, and a larger peak area corresponds to relatively higher crystallinity and vice versa. Therefore, the structural changes (e.g., structural disorder) due to charge/discharge energy storage will inevitably leads experimentally to the evolution of band intensities. Therefore, revealing the crystal structural information on c-Si through in-operando Raman testing is ideally suitable to obtain a clear relationship between the structural features and $\mathrm{Na}^{+}$insertion/extraction. The intensity changes in the Si peaks are summarized in Figure 2b. It is revealed that the relative intensity of the Si peaks first decreased significantly after the initial discharge process $(0-4500 \mathrm{~s})$, corresponding to the reduction peaks at $0.75 \mathrm{~V}$ (from $0.5 \mathrm{~V}$ to $1.5 \mathrm{~V}$ ) and $0.2 \mathrm{~V}$ (from $0.01 \mathrm{~V}$ to $0.5 \mathrm{~V}$ ) in the $\mathrm{CV}$ profile. Then the decrease slowed down in the following charge process (4,500-12,000 s), and the peak intensities remained stable for the rest of the cycling test $(12,000-30,000 \mathrm{~s})$. Because the reduction peak at $0.5-1.5 \mathrm{~V}$ disappeared during the second cycle, the first intensity decrease in the range of $0-3250$ s should be related to the formation of SEI film during the first discharge process. The intensity then decreased from 3250-4500 s. This corresponds to another reduction peak from $0.01 \mathrm{~V}$ to $0.5 \mathrm{~V}$, demonstrating the $\mathrm{Na}^{+}$ 


\section{Submitted to

uptake and the alloying process with c-Si. After the first discharge process, the intensity of the Si peak remained almost stable, which means that the intensity decrease from $\mathrm{Na}^{+}$insertion was irreversible. Therefore, we believe that the crystallinity of c-Si experienced a considerable irreversible decrease during the first cycling test, resulting in more of the disordered a-Si structure in the c-Si (which can be testified by the HRTEM images and their corresponding FFT patterns in Figure S4). HRTEM images indicate the crystalline nature of original c-Si nanoparticles (Figure S4a) and an increasing content of the amorphous structure in the subsequent cycle (Figure S4b and S4c), which agrees well with the Raman results. Furthermore, the crystal structural conversion of the c-Si electrode was explored in detail by ex-operando Raman spectra. Figure 2c shows the Raman profiles of the original c-Si and the c-Si after one electrochemical cycle. It can be found that the intensity of the Si peak decreased directly from 6800 a.u. to 1000 a.u. after the first cycle. In addition, a certain amount of a-Si could be observed after one cycle (inset of Figure 2c). The ratio of the peak areas between a$\mathrm{Si}$ and $\mathrm{c}-\mathrm{Si}$ is about $3: 1$, which means that more than $75 \%$ of the c-Si was converted to a-Si after the first sodiation process.

Therefore, an irreversible crystal structure transformation from c-Si to a-Si takes place during the first sodiation process and this newly generated a-Si is beneficial for the reversible $\mathrm{Na}^{+}$ insertion reaction due to its more disordered crystal structure. Unfortunately, because a-Si has a larger lattice spacing than that of $\mathrm{c}-\mathrm{Si}$, the volume of the original c-Si will inevitably increase during this sodiation process. The structural integrity will also be destroyed, leading to a degradation of the original structure and the decrease of the effective conductive contact between the electrode skeleton and the active materials (similar to the c-Si'-behavior in LIBs). As a result, the pure nanosized c-Si electrode shows poor structural and cycling stability.

The diagrams in Figure $\mathbf{S 5}$ schematically illustrate the process for the c-Si planes collapse. The whole process includes four phases along with an growing degree of sodiation. In stage one, $\mathrm{Na}$ ions diffuse along the ion channels and accumulate at tetrahedral sites between (111) 
planes because this position is the most stable site for Li- or Na-ion insertion (highlighted as greenish regions in Figure S5a). ${ }^{[30-34]}$ In stage two, along with the concentration of $\mathrm{Na}^{+}$grows, the bonds of $\mathrm{Si}-\mathrm{Si}$ are broken, and $\mathrm{Na}$ atoms make new bonds with $\mathrm{Si}$ atoms in stable positions (Figure S5b). In stage three, further sodiation leads to the break of majority of the $\mathrm{Si}-\mathrm{Si}$ bonds, and crystal Si transformed into an amorphous Na-Si alloy (Figure S5c). In stage four, after the desodiation process, the amorphous structure is maintained, leading to the a-Si structure (Figure S5d).

To enhance the architectural stability and the conductivity of c-Si (Figure S6), we design a unique nanoarchitectured $\mathrm{Si} / \mathrm{C}$ composite. It is demonstrated that only limited sodiation can proceed in the microsized c-Si, due to the limited active positions. In contrast, the sodiation process could be more easily realized in the nanosized c-Si. However, the nanosized c-Si experiences large volume expansion after the first sodiation, resulting in structural pulverization. Therefore, a yolk-shell structure inside the 1-D structure of the Si/C composite is reasonable for improving the structural stability and also the conductivity. Yolk-shell structured $\mathrm{Si} / \mathrm{C}$ nanobeads distributed within the $1 \mathrm{D}$ carbon nanofibers lead to a bamboorattle like Si/C composite. Even after the sodiation process, the cracked c-Si particles can still be well maintained inside the hollow carbon spheres, avoiding the direct exposure of the electrodes in the electrolyte.

Figure 3 illustrates the synthesis procedure for the Si/C composite. c-Si NPs are first coated with silica to obtain the $\mathrm{SiO}_{2} / \mathrm{Si}$ composite, and then the $\mathrm{SiO}_{2} / \mathrm{Si}$ composite is mixed with polyacrylonitrile (PAN) via an electrospinning process to prepare the $\mathrm{SiO}_{2} / \mathrm{Si} / \mathrm{PAN}$ nanofibers. After the carbonization and HF treatment, the flexible $\mathrm{Si} / \mathrm{C}$ film composed of $\mathrm{Si} / \mathrm{C}$ nanofibers is obtained. A single $\mathrm{Si} / \mathrm{C}$ nanofiber is also shown in the center of Figure 3 along with its enlarged cross section from one end. Yolk-shell structured CVS is embedded inside the bamboo-like $\mathrm{Si} / \mathrm{C}$ nanofiber, leading to a bamboo-rattle structured $\mathrm{Si} / \mathrm{C}$ composite. Figure $\mathbf{S} 7$ shows the $\mathrm{SEM}$ image for the $\mathrm{SiO}_{2} @ \mathrm{Si}$ particles. The coating layers of silica were 


\section{Submitted to

successfully created on each Si NP. Comparing with the pure nanosized c-Si in 1c, the diameters of Si NPs obviously increase from around $80-120 \mathrm{~nm}$ to $100-160 \mathrm{~nm}$ due to the silica coating on the outer surface. Therefore, the thickness of the silica sacrificial layer is in the range of 10-20 nm. Figure 4 reveals the SEM images of the final $\mathrm{Si} / \mathrm{C}$ composites. The nanofibers from all the samples are well interconnected, leading to a connected three dimensional (3D) network. The average diameter of the nanofibers was around 300-500 nm. A series of bead-like expansions can be found along the bamboo-structured nanofibers. In addition, with increasing the c-Si content, the surface of the carbon nanofibers becomes much rougher, and the size of the interior bead-like expansions is also increased. This phenomenon becomes quite obvious when the $\mathrm{SiO}_{2} @ \mathrm{Si}$ content is increased to $0.7 \mathrm{~g}$, which is mainly due to the poor dispersion of $\mathrm{SiO}_{2} @ \mathrm{Si}$ particles in the solvent for the electrospinning process. The typical TEM results of the final Si/C composites are also shown in Figure 4. With increasing the content of the active materials, more CVS nanobeads can be found inside the nanofibers, leading to much more irregular morphologies. Although the contents of $\mathrm{SiO}_{2} @ \mathrm{Si}(0.4 \mathrm{~g}, 0.5 \mathrm{~g}$ to $0.6 \mathrm{~g}$ ) are different, the sizes of the CVS are nearly the same. The diameter of a whole CVS nanofiber is typically around 150-160 nm. The SEM pictures of c-Si and $\mathrm{SiO}_{2} @ \mathrm{Si}$ display that all the nanoparticles have slight agglomeration. Nevertheless, the TEM images clearly show that Si NPs are separate from each other with a void space between them. It is believed that the uniform coating of silica and the following treatment by HF can improve the CVS distribution inside the nanofibers. TEM observations indicate that the silica coatings could be completely removed after HF treatment, suggesting that the HF solution could go through the CNF wall. As a result, it is reasonable that few amount of the electrolyte could also penetrate the CNF wall during the cycling of our tested cells. Owing to the formation of SEI layers on the outer surface of CNFs during initial cycles, however, it is believed that the electrolyte could be effectively limited to go through the CNF wall in the subsequent cycles. 


\section{Submitted to

The mechanical properties (mechanical intensity and flexibility) of the final products play important roles in the practical application of flexible electrodes. Since an atomic force microscopy (AFM) system can be satisfied to accurately employ nano- and pico-Newton ranged forces to detect the nanoscale ranged deformation, it is an extremely helpful instrument for the investigating the mechanical properties of nanosized materials. The working principle of this tool is depended on the interaction between the sample and AFM tip upon contact or near contact, in the so-called three-point bend measurement. Therefore, it is ideally available for revealing the flexibility of the nanosized Si/C fibers. Figure S8a shows a model of this three-point bend test system. One single $\mathrm{Si} / \mathrm{C}$ nanofiber with the AFM tip pressed upon it is suspended over a void between two nanofibers. Figure S8b shows the relationship between the deformation distance and the voltage. The pressure force imposed on the nanofiber has a relationship with the voltage. The higher the voltage, the bigger was the pressure on the sample. Therefore, based on the ratio between the distance $(D)$ and the voltage ( $V)(\mathrm{d} D / \mathrm{d} V)$, the flexibility differences between the different samples could be obtained. The $\mathrm{d} D / \mathrm{d} V$ of the straight line section in the profiles of $\mathrm{Si} / \mathrm{C}-1, \mathrm{Si} / \mathrm{C}-2, \mathrm{Si} / \mathrm{C}-3$, and $\mathrm{Si} / \mathrm{C}-4$ is around $283,270,250$, and $180 \mathrm{~nm} \mathrm{~V}^{-1}$, respectively. In order to guarantee the reliability and repeatability of the results for each sample, nine different positions in each sample were also investigated. It is found that all these data were distributed in a narrow range. Si/C-1 shows the best flexibility, while Si/C-4 has the worst. However, no big difference in the flexibility can be found among the $\mathrm{Si} / \mathrm{C}-1, \mathrm{Si} / \mathrm{C}-2$ and $\mathrm{Si} / \mathrm{C}-3$ samples. If we take the contents of the active materials (c-Si) in the $\mathrm{Si} / \mathrm{C}$ composites into consideration, the $\mathrm{Si} / \mathrm{C}-3$ is endowed with a high active material content along with good flexibility. Therefore, Si/C-3 would have a higher specific capacity and also the possibility for the binder-free flexible cell fabrication. Si/C-3 membrane recovers its initial state easily after folding and manipulation, indicating its excellent mechanical durability (Figure S8c). Si/C-3 as the preferred sample was chosen for the following electrochemical tests. 
Submitted to

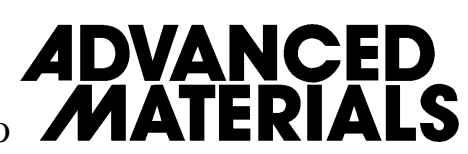

Figure S8d illustrates the XRD results of $\mathrm{Si} / \mathrm{C}-3$ and CNFs. Three distinct diffraction peaks at $2 \theta$ values of $28.3^{\circ}, 47.0^{\circ}$, and $55.8^{\circ}$ can be ascribed to the Si phase's (111), (220) and (311) plans, respectively. Apart from them, another peak at around $25.0^{\circ}$ can be associated with the carbon's (002) planes. The intensity of (002) peak is very weak, which means that this carbon material has a low graphitization degree. Figure S8e shows the Thermogravimetric (TG) curve of the Si/C-3 sample in air. The weight loss caused by carbon combustion is started from $450{ }^{\circ} \mathrm{C}$ and ended at about $670{ }^{\circ} \mathrm{C}$. The residual mass of Si/C-3 at $670{ }^{\circ} \mathrm{C}$ is around 20 wt $\%$, suggesting the relevant amount of c-Si. In addition, a slight weight increase can be found after $670{ }^{\circ} \mathrm{C}$, which is mainly assigned to the oxidation of c-Si at high temperature in air.

Figure 5a shows the initial/second discharge and charge profiles of $\mathrm{Si} / \mathrm{C}-3$ at a current density of $50 \mathrm{~mA} \mathrm{~g}^{-1}$. The discharge and charge capacities in the first cycle are 813.7 and $438.0 \mathrm{mAh}$ $\mathrm{g}^{-1}$, leading to an initial Coulombic efficiency of $53.8 \%$. During the first discharge, the sloping voltage plateaus which disappear in the second cycle between 1.0 and $0.4 \mathrm{~V}$ illustrate the formation of the stable SEI film on the outer surface of the electrode, corresponding to the reduction $\mathrm{CV}$ peak at around $0.5 \mathrm{~V}$ in Figure 5b. A flat voltage plateau below $0.4 \mathrm{~V}$ is consistent with the reduction peak at about $0.2 \mathrm{~V}$, indicating the insertion of sodium ions in cSi. Furthermore, the voltage plateaus around $0.5 \mathrm{~V}$ during the charge processes in the chargedischarge profiles and also the corresponding oxidation peaks below $0.5 \mathrm{~V}$ in the $\mathrm{CV}$ curves are related to the extraction of $\mathrm{Na}^{+}$from Si. Compared with the pure c-Si electrode, a new pair of redox peaks in the range of $0.5-2.0 \mathrm{~V}$ can be found in the $\mathrm{CV}$ profiles of $\mathrm{Si} / \mathrm{C}$, indicating the extraction of $\mathrm{Na}^{+}$from CNFs.

The cycling performance in Figure 5c reveals that the charge capacity of Si/C-3 from 0.01 to $3 \mathrm{~V}$ at $50 \mathrm{~mA} \mathrm{~g}^{-1}$ is $438.2 \mathrm{mAh} \mathrm{g}^{-1}$ at the first cycle and $454.5 \mathrm{mAh} \mathrm{g}^{-1}$ after 200 cycles, indicating that $\mathrm{Si} / \mathrm{C}-3$ has an excellent cyclability. In addition, the charge capacity of pure carbon nanofibers derived from pure PAN is $154.7 \mathrm{mAh} \mathrm{g}^{-1}$ at the first cycle and $156.9 \mathrm{mAh}$ 
Submitted to

$\mathrm{g}^{-1}$ after 200 cycles. Compared with CNFs, the higher capacity $290 \mathrm{mAh} \mathrm{g}^{-1}$ of $\mathrm{Si} / \mathrm{C}-3$ is derived from the introduction of c-Si. Figure $5 \mathrm{~d}$ shows the rate performance of $\mathrm{Si} / \mathrm{C}-3$ at different current densities. The charge capacity of Si/C-3 at $50 \mathrm{~mA} \mathrm{~g}^{-1}$ after the first 20 cycles is $408.5 \mathrm{mAh} \mathrm{g}^{-1}$, and the capacity retention at $100,500,1000,2000$ and $5000 \mathrm{~mA} \mathrm{~g}^{-1}$ after 20 cycles is $94.5,89.1,81.6,75.4$ and $65.9 \%$, respectively. Furthermore, the long-term cycling performance of $\mathrm{Si} / \mathrm{C}-3$ at a higher current density of $5000 \mathrm{~mA} \mathrm{~g}^{-1}$ is shown in Figure 5e. TG results indicate that there are $20 \mathrm{wt} \%$ of silicon inside the $\mathrm{Si} / \mathrm{C}-3$ sample. In addition, based on the theoretical capacity of Si (about $960 \mathrm{mAh} \mathrm{g}^{-1}$ ) and hard carbon (around 300 $\mathrm{mAh} \mathrm{g}^{-1}$ ) as anoded in SIBs, the $1 \mathrm{C}$ rate for Si/C-3 should be $432 \mathrm{~mA} \mathrm{~g}^{-1}$. The discharge capacity of $\mathrm{Si} / \mathrm{C}-3$ is maintained at about $75 \%$ even after 2000 cycles at a very high current density (over $10 \mathrm{C}, 1 \mathrm{C}=432 \mathrm{~mA} \mathrm{~g}^{-1}$ ). Therefore, the as-prepared Si/C-3 is endowed with the excellent cyclability and rate performance. In order to systematically understand the whole profiles about the alloy anodes for sodium storage, we provide a summary in Table S1 to compare our Si-based alloy electrode with other alloy materials. The TEM image of Si/C-3 upon continuous cycling is shown in Figure S9. We can see that a structural pulverization of c-Si happens inside Si/C-3 after cycling test. c-Si nanoparticles are broken into smaller particles in an amorphous state. Fortunately, all of these smaller-sized particles are well maintained inside the porous CNFs, which is exactly ascribed to our novel structural design. The bamboo-rattle structured $\mathrm{Si} / \mathrm{C}$ created here shows excellent electrochemical properties with good cycling stability and ultra-fast $\mathrm{Na}^{+}$-storage capability. This is mainly because of its unique architecture: (1) the introduction of the interconnected 1D carbon nanofiber network can effectively strengthen the mechanical properties, improve the electrical conductivity, and prevent electrolyte ingress; and (2) the yolk-shell structure developed inside can not only provide additional storage sites for $\mathrm{Na}^{+}$and promote $\mathrm{Na}^{+}$transfer and electrolyte diffusion, but also provide better absorption of the huge volume changes of c-Si during cycling, prevent the aggregation of Si NPs, and allow for the growth of a stable SEI film. 
hanism of nanocrystalline silicon during

In summary, we report the sodiation/desodiation mechanism of nanocrystalline silicon during the $\mathrm{Na}^{+}$insertion/extraction processes. It is found that an irreversible crystal structure conversion from crystalline silicon to amorphous silicon takes place during the first discharge process, leading to reversible $\mathrm{Na}^{+}$insertion in the newly generated amorphous silicon. Furthermore, in order to overcome the poor conductivity and inferior structural stability of a$\mathrm{Si}$, an attractive well-defined bamboo-rattle-like architecture is designed. The rationally designed, interconnected, 3D carbon framework, which is made of yolk-shell carbon/silicon nanobeads embedded in 1D carbon nanofibers, endows this silicon-based SIB electrode with excellent electrochemical Na-storage performances. In addition, this 3D carbon framework is flexible and also has good mechanical strength, which can serve directly as binder-free anodes for SIBs. Therefore, we believe that nanocrystalline silicon is a very promising anode material in sodium ion batteries, taking advantages of a designed structure.

\section{Experimental Section}

Materials: All the reagents used were obtained from Sigma Aldrich. Commercial c-Si NPs were first coated with a $\mathrm{SiO}_{2}$ layer $\left(\mathrm{SiO}_{2} @ \mathrm{Si}\right)$ using tetraethoxysilane. SiNPs (150 mg) were first dispersed in a mixture of ethanol $(240 \mathrm{~mL})$ and water $(60 \mathrm{~mL})$ under ultrasonication, followed by addition of concentrated ammonium hydroxide $(3.0 \mathrm{~mL})$. Under vigorous stirring, $2.4 \mathrm{~g}$ of tetraethoxysilane (TEOS, Aldrich) was added dropwise into the dispersion and the reaction was kept at room temperature under stirring for $12 \mathrm{~h}$. The $\mathrm{SiO}_{2}$-coated $\mathrm{SiNPs}$ were collected by centrifugation, and washed for three times by water. $\mathrm{Si} @ \mathrm{SiO}_{2} /$ polyacrylonitrile $\left(\mathrm{SiO}_{2} @ \mathrm{Si} / \mathrm{PAN}\right)$ nanofibers were first electrospun on a piece of aluminium foil from a precursor solution that contained $\mathrm{SiO}_{2} @ \mathrm{Si}(0.4 \mathrm{~g}), \mathrm{PAN}$ (average $M \mathrm{w}=150,000,1.0 \mathrm{~g}$ ), and $\mathrm{N}, \mathrm{N}$-dimethylformamide (DMF, $10 \mathrm{~mL}$ ). The voltage of $17 \mathrm{kV}$ was applied over a collector distance of $10 \mathrm{~cm}$ and the flow rate was fixed at $1 \mathrm{~mL} \mathrm{~h}^{-1}$. A film of $\mathrm{SiO}_{2} @ \mathrm{Si} / \mathrm{PAN}$ nanofiber web was then peeled off from the collector after electrospinning. The flexible binder-free film 
Submitted to

made of bamboo-rattle type $\mathrm{Si} / \mathrm{C}$ nanofibers was finally obtained after calcining at $600{ }^{\circ} \mathrm{C}$ for $2 \mathrm{~h}$ in $5 \% \mathrm{Ar} / \mathrm{H}_{2}$ and then etching the $\mathrm{SiO}_{2}$ in $10 \mathrm{wt} \% \mathrm{HF}$ aqueous solution at room temperature for $30 \mathrm{~min}$. The as-obtained sample was denoted as $\mathrm{Si} / \mathrm{C}-1$.

For comparison, different $\mathrm{Si} / \mathrm{C}$ composites with different $\mathrm{Si}$ contents were fabricated under the same conditions as described above except that $0.5,0.6$ or $0.7 \mathrm{~g} \mathrm{SiO}_{2} @ \mathrm{Si}$ was added and the samples were denoted as $\mathrm{Si} / \mathrm{C}-2, \mathrm{Si} / \mathrm{C}-3$ and $\mathrm{Si} / \mathrm{C}-4$, respectively. In addition, pure PAN without $\mathrm{SiO}_{2} @ \mathrm{Si}$ was also prepared. After the electrospinning of the PAN solution, it was subjected to a calcination process at $600{ }^{\circ} \mathrm{C}$ for $2 \mathrm{~h}$ in $\mathrm{Ar} / \mathrm{H}_{2}(95 / 5$ by volume) atmosphere to obtain the final pure carbon, identified as carbon nanofibers (CNFs).

Materials Characterization: The morphology and microstructure of the products were characterized by scanning electron microscopy (SEM, FEI, Sirion 200). Transmission electron microscopy (TEM) and high-resolution TEM (HRTEM) images were obtained with a Tecnai G2 F30 (FEI, Holland). Thermogravimetric (TG) analysis was carried out with a PerkinElmer Diamond TG/DTA apparatus. X-ray diffraction (XRD) studies were carried out using a X'Pert PRO (PANalytical B.V., Epsilon 5, Holland) diffractometer with high intensity $\mathrm{Cu} \mathrm{K \alpha 1}$ irradiation $(\lambda=1.5406 \AA)$. The in-operando XRD measurements were conducted by combining an electrochemical workstation (CHI 760D) and two-dimensional (2D) XRD (Bruker D8 DISCOVER). Raman spectroscopy was conducted on a LabRAM HR Evolution system employing a $10 \mathrm{~mW}$ helium/neon laser at $514.5 \mathrm{~nm}$. In-operando Raman testing was conducted on a LabRAM HR Evolution system equipped with deep-depleted thermoelectrically cooled charge-coupled device (CCD) array detector and an Ar laser (wavelength $=514.5 \mathrm{~nm}$ ). Raman spectra of the samples were captured one by one via a mapping mode (one spectrum per 250 seconds) while cyclic voltammetry was conducted in an in-operando Raman cell at a sweep rate of $0.4 \mathrm{mV} \mathrm{s}^{-1}$. Atomic force microscopy (AFM) in a tapping mode was employed for the three-point bending tests on $\mathrm{Si} / \mathrm{C}$ nanofibers. 


\section{Submitted to

Electrochemical measurements: Electrochemical testing was conducted on coin-type half cells assembled in an argon-filled glove box. A sodium foil was employed as both the reference and counter electrodes, and the self-supported $\mathrm{Si} / \mathrm{C}$ film $(5-10 \mathrm{mg})$ as the working electrode. $1 \mathrm{~mol} \mathrm{~L} \mathrm{LaClO}_{4}$ in a mixture of ethylene carbonate (EC) and polypropylene carbonate (PC) (1:1 by volume) with 5 vol\% addition of fluoroethylene carbonate (FEC) was used as the electrolyte, and the Whatman glassfiber was used for the separator. Electrochemical cycling of electrodes was conducted at $50-5000 \mathrm{~mA} \mathrm{~g} \mathrm{~g}^{-1}$ for galvanostatic measurements during the 0.01 to $3.0 \mathrm{~V}\left(\mathrm{vs} . \mathrm{Na} / \mathrm{Na}^{+}\right.$) potential window. Cyclic voltammetry was performed using a Biologic VMP-3 electrochemical workstation between 0.01 and $3.0 \mathrm{~V}$ at scan rates of $0.1-20 \mathrm{mV} \mathrm{s}^{-1}$. The capacities were calculated based on the total mass of $\mathrm{Si}$ and CNFs.

\section{Supporting Information}

Supporting Information is available online from the Wiley Online Library or from the author.

\section{Acknowledgements}

This work is supported by the National High-tech R\&D Program of China (863 Program, No. 2015AA034601), National Natural Science Foundation of China (No. 51522205, 51472098 and 21271078), and Baosteel-Australia Joint Research \& Development Centre (BAJC), Project BA14006, Auto CRC 2020, Project 1-117 and ARENA Smart Sodium Storage System (S4) project. Lei Zhang would like to express his gratitude for his China Scholarship Council (CSC) scholarships from China. The authors would like to also thank Dr. Tania Silver for critical reading of the manuscript. They also acknowledge the use of the facilities in the Wuhan University of Technology and South China University of Technology, with particular thanks to Dr. Jiashen Meng, Dr. Peng Wu, and Dr. Fenghua Zheng. 
Submitted to

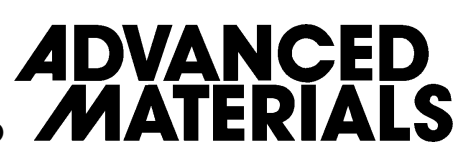

Received: ((will be filled in by the editorial staff))

Revised: ((will be filled in by the editorial staff)) Published online: ((will be filled in by the editorial staff))

[1] Y. Xu, E. Swaans, S. Basak, H. W. Zandbergen, D. M. Borsa and F. M. Mulder, Adv. Energy Mater. 2015, 12, 1501436.

[2] Y. C. Liu, N. Zhang, L. F. Jiao and J. Chen, Adv. Mater. 2015, 27, 6702-6707.

[3] Y. Park, D. S. Shin, S. H. Woo, N. S. Choi, K. H. Shin, S. M. Oh, K. T. Lee and S. Y. Hong, Adv. Mater. 2012, 24, 3562-3567.

[4] D. A. Stevens and J. R. Dahn, J. Electrochem. Soc. 2000, 147, 1271.

[5] D. A. Stevens and J. R. Dahn, J. Electrochem. Soc. 2001, 148, A803.

[6] S. Wenzel, T. Hara, J. Janek and P. Adelhelm, Energy Environ. Sci. 2011, 4, 3342.

[7] Y. Xu, Y. Zhu, Y. Liu and C. Wang, Adv. Energy Mater. 2013, 3, 128-133.

[8] Z. Liu, X. Yu, X. Lou and U. Paik, Energy Environ. Sci. 2016, 9, 2314-2318.

[9] L. Zhang, X. Liu, Q. Zhao, S. Dou, H. Liu, Y. Huang and X. Hu, Energy Stor. Mater. 2016, 4, 92-102.

[10] L. Zhang, H. Guo, R. Ranjusha, X. Hu, Y. Huang, S. Dou and H. Liu, J. Mater. Chem. A 2016, 4, 4056-4061.

[11] L. Zhang, R. Rajagopalan, H. P. Guo, X. L. Hu, S. X. Dou and H. K. Liu, Adv. Funct. Mater. 2016, 26, 440-446.

[12] L. Zhang, M. J. Zhang, Y. H. Wang, Z. L. Zhang, G. W. Kan, C. G. Wang, Z. Y.

Zhong and F. B. Su, J. Mater. Chem. A 2014, 2, 10161-10168.

[13] L. Zhang, Y. H. Wang, G. W. Kan, Z. L. Zhang, C. G. Wang, Z. Y. Zhong and F. B. $\mathrm{Su}, \operatorname{Rsc} A d v . \mathbf{2 0 1 4}, 4,43114-43120$.

[14] H. Moritoa, T. Yamada, T. Ikedab and H. Yamane, J. Alloys Compd. 2009, 480, 723726. 
[15] T. Kume1, Y. Iwai, T. Sugiyama, F. Ohashi, T. Ban, S. Sasaki and S. Nonomura, Phys. Status Solidi C 2013, 10, 1739-1741.

[16] N. Liu, H. Wu, M. T. McDowell, Y. Yao, C. Wang and Y. Cui, Nano Lett. 2012, 12, $3315-3321$.

[17] L. G. Xue, K. Fu, Y. Li, G. J. Xu, Y. Lu, S. Zhang, O. Toprakci and X. W. Zhang, Nano Energy 2013, 2, 361-367.

[18] Y. Li, G. J. Xu, Y. F. Yao, L. G. Xue, S. Zhang, Y. Lu, O. Toprakci and X. W. Zhang, J Solid State Electr. 2013, 17, 1393-1399.

[19] J. Q. Wang, Y. Yu, L. Gu, C. L. Wang, K. Tang and J. Maier, Nanoscale 2013, 5, 2647-2650.

[20] L. W. Ji and X. W. Zhang, Energy Environ. Sci. 2010, 3, 124-129.

[21] L. W. Ji, K. H. Jung, A. J. Medford and X. W. Zhang, J. Mater. Chem. 2009, 19, $4992-4997$.

[22] T. H. Hwang, Y. M. Lee, B. S. Kong, J. S. Seo and J. W. Choi, Nano Lett., 2012, 12, 802-807.

[23] L. W. Ji and X. W. Zhang, Carbon 2009, 47, 3219-3226.

[24] Z. X. Dong, S. J. Kennedy and Y. Q. Wu, J. Power Sources 2011, 196, 4886-4904.

[25] Y. P. Liu, K. Huang, Y. Fan, Q. Zhang, F. Sun, T. Gao, Z. Z. Wang and J. X. Zhong, Electrochim. Acta 2013, 102, 246-251.

[26] S. Cavaliere, S. Subianto, I. Savych, D. J. Jones and J. Roziere, Energy Environ. Sci. 2011, 4, 4761-4785.

[27] N. Liu, Z. Lu, J. Zhao, M. T. McDowell, H. W. Lee, W. Zhao and Y. Cui, Nat. Nanotechnol. 2014, 9, 187-192.

[28] H. Wu, M. R. Hartman, T. J. Udovic, J. J. Rush, W. Zhou, R. C. Bowman, Jr. and J. J. Vajo, Acta Crystallogr. B 2007, 63, 63-68. 
[29] C. Chen, Y. Wen, X. Hu, X. Ji, M. Yan, L. Mai, P. Hu, B. Shan and Y. Huang, Nat.

Commun. 2015, 6, 6929.

[30] S. W. Lee, M. T. McDowell, J. W. Choi and Y. Cui, Nano Lett. 2011, 11, 3034-3039.

[31] Q. Zhang, W. Zhang, W. Wan, Y. Cui and E. Wang, Nano Lett. 2010, 10, 3243-3249.

[32] W. Wan, Q. Zhang, Y. Cui and E. Wang, J. Phys. Condens. Matter. 2010, 22, 415501.

[33] Y. Yu, L. Gu, C. Zhu, S. Tsukimoto, P. A. van Aken and J. Maier, Adv. Mater. 2010, $22,2247-2250$.

[34] J. Liu, P. Kopold, P. A. van Aken, J. Maier and Y. Yu, Angew. Chem. Int. Ed. 2015, 54, 9632-9636. 


\section{Submitted to
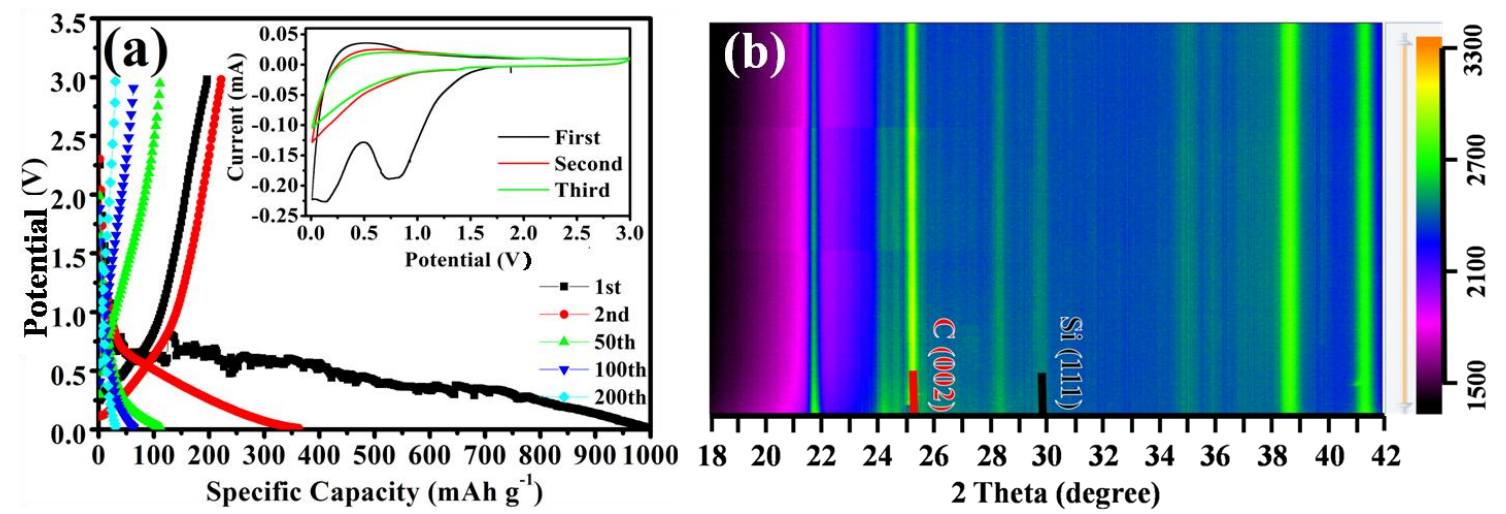

Figure 1. Electrochemical performance of the nanosized c-Si and microsized c-Si

electrodes. (a) Charge-discharge profiles for selected cycles at $500 \mathrm{~mA} \mathrm{~g}^{-1}$ (inset: the first three CV curves for the nanosized c-Si electrode), and (b) in-operando XRD data for microsized c-Si. 


\section{Submitted to
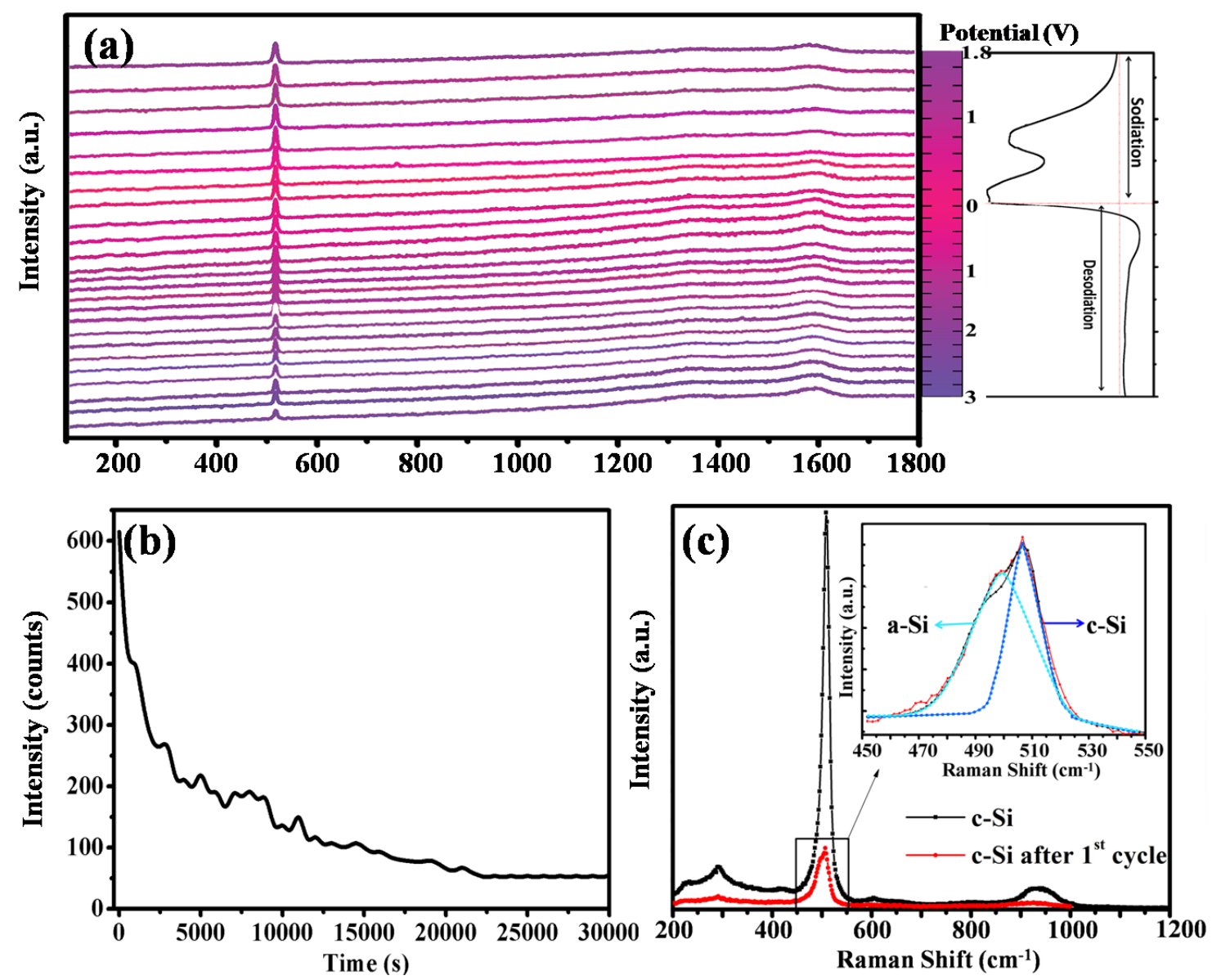

Figure 2. In-operando Raman analysis of the electrochemical behavior towards $\mathrm{Na}^{+}$for the nanosized c-Si electrode. (a) in-operando Raman results along with the first cycle CV profile of nanosized c-Si, (b) intensity changes verses time, and (c) ex-operando Raman spectra of nanosized c-Si before and after the first cycle (inset: enlargement of the indicated region between 450 and $550 \mathrm{~cm}^{-1}$ ) 


\section{ADVANCED
MATERIALS}

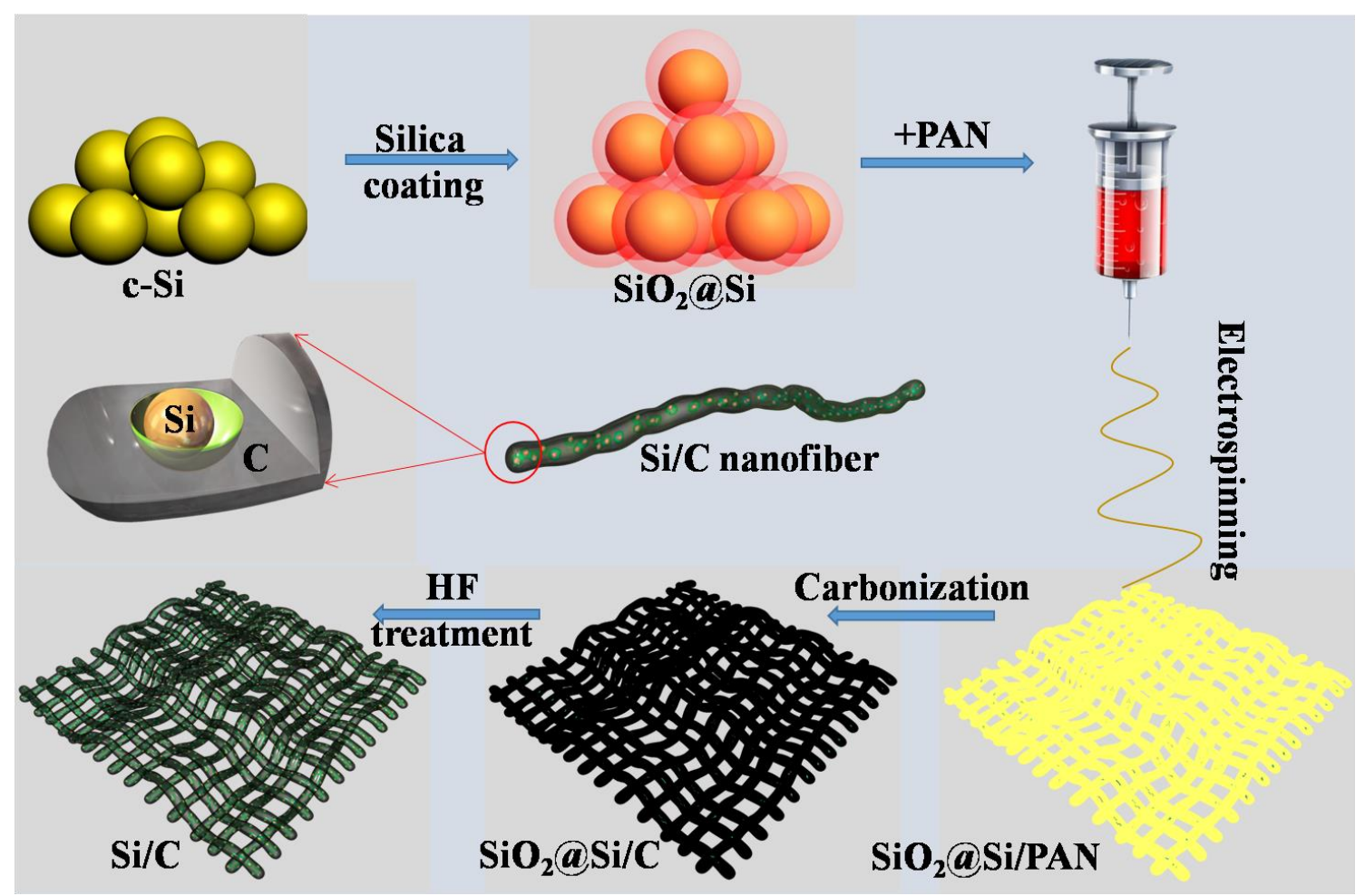

Figure 3. Schematic representation of the $\mathrm{Si} / \mathrm{C}$ composite design. 


\section{Submitted to \\ ADVANCED MATERIALS}

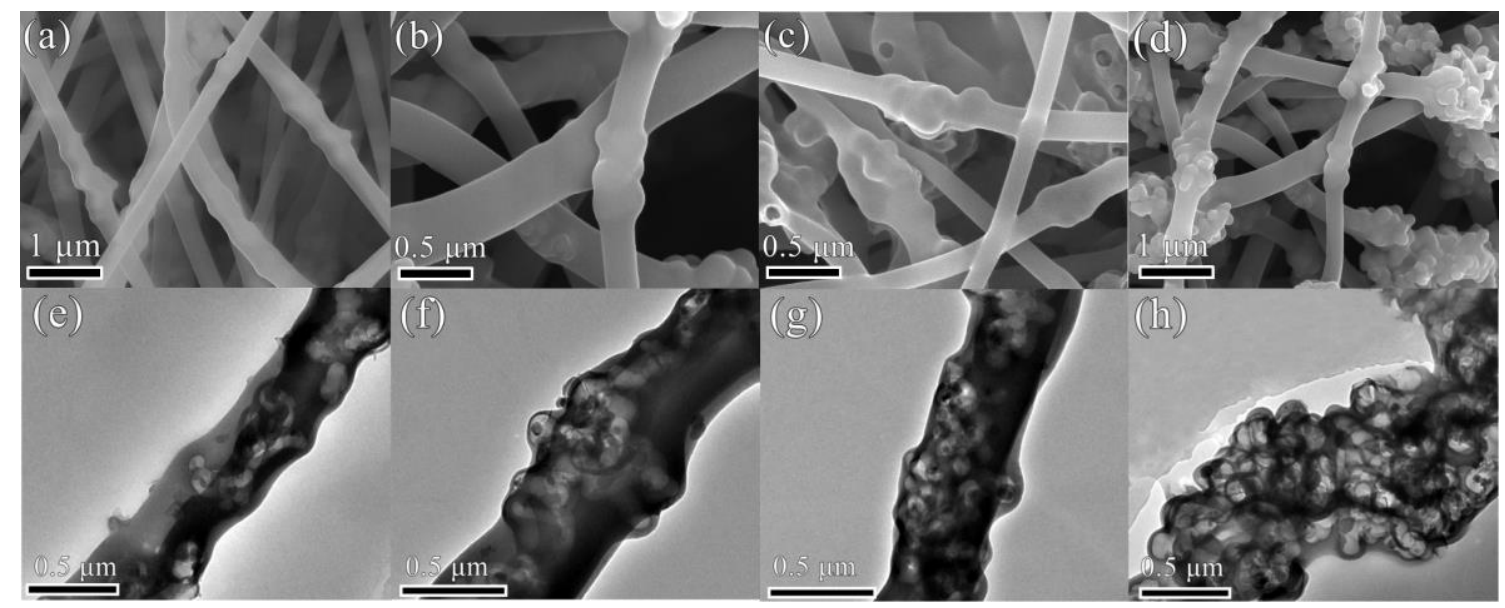

Figure 4. Morphology and bamboo-rattle-like architecture of the Si/C composites. SEM (above) and TEM (below) images of the synthesized $\mathrm{Si} / \mathrm{C}$ samples with different $\mathrm{SiO}_{2} @ \mathrm{Si}$ contents: Si/C-1 (a and e), Si/C-2 (b and f), Si/C-3 (c and g), and Si/C-4 (d and h). 

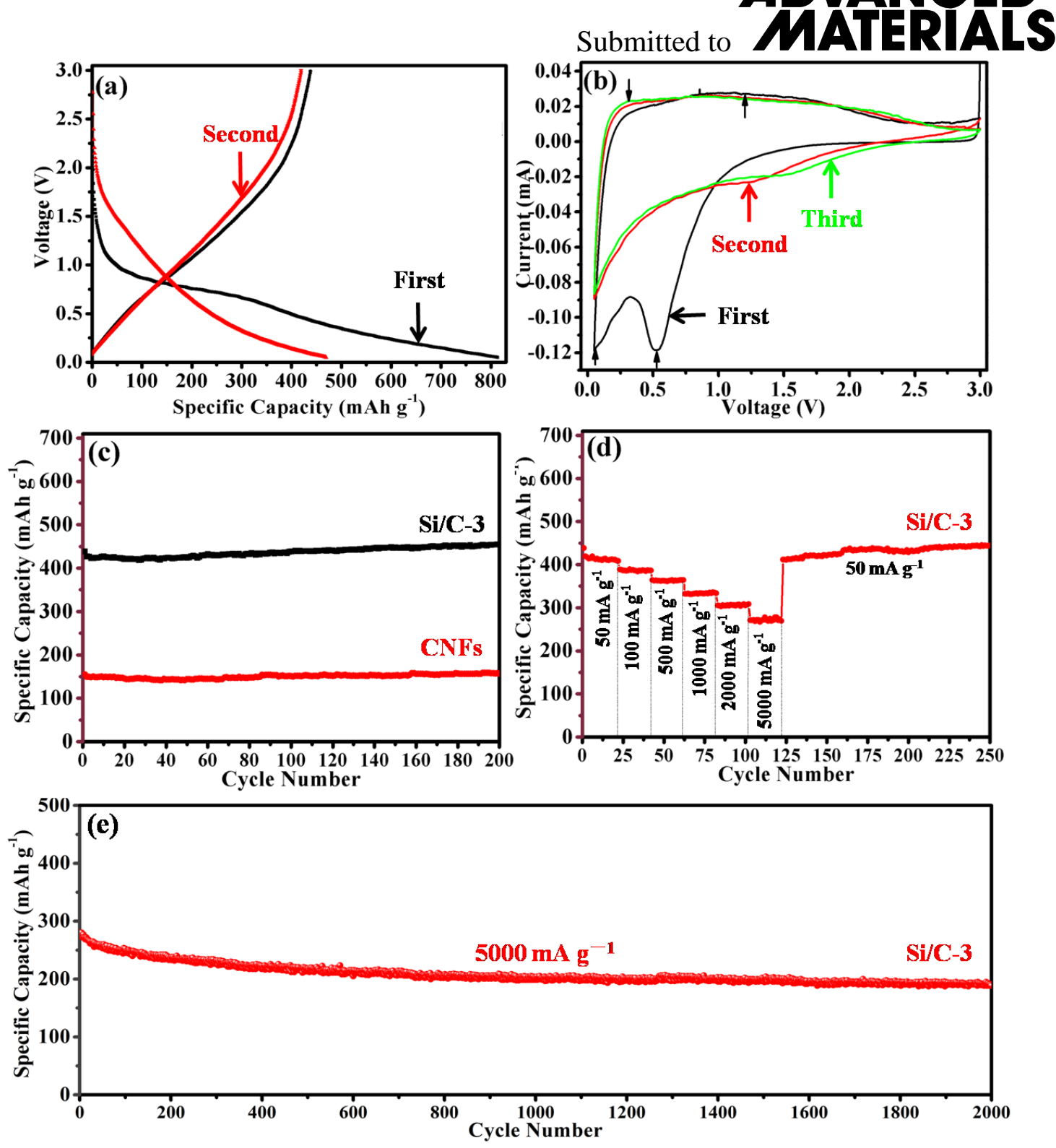

Figure 5. Electrochemical performance of the samples. (a) initial and second cycle chargedischarge profiles of Si/C-3 at a current density of $50 \mathrm{~mA} \mathrm{~g}^{-1}$, (b) the first three $\mathrm{CV}$ curves of $\mathrm{Si} / \mathrm{C}-3$ at a scan rate of $0.1 \mathrm{mV} \mathrm{s}^{-1}$, (c) the cycling performance of Si/C-3 and pure CNFs at a current rate of $50 \mathrm{~mA} \mathrm{~g}^{-1}$, (d) the rate performance of Si/C-3 at different current densities, and (e) long-term cycling test at a current density of $5000 \mathrm{~mA} \mathrm{~g}^{-1}$ (over $10 \mathrm{C}$ ). 
The electrochemical mechenizm of nanocrystalline silicon anode in sodium ion batteries was first studied via in-operando Raman and in-operando XRD. An irreversible structural conversion from crystalline silicon to amorphous silicon takes place during the initial cycles, leading to ultra-fast reversible sodium insertion in the newly generated amorphous silicon. Furthermore, an optimized silicon/carbon composite has been developed to further improve its electrochemical performance.

Keyword: nanocrystal silicon, in-operando analysis, anode, sodium ion battery

Lei Zhang, Xianluo Hu,* Chaoji Chen, Haipeng Guo, Xiaoxiao Liu, Gengzhao Xu, Haijian Zhong, Shuang Cheng, Peng Wu, Jiashen Meng, Yunhui Huang,* Shixue Dou, Huakun Liu*

In-operando mechanism analysis on nanocrystalline silicon anode material for reversible and ultra-fast sodium storage

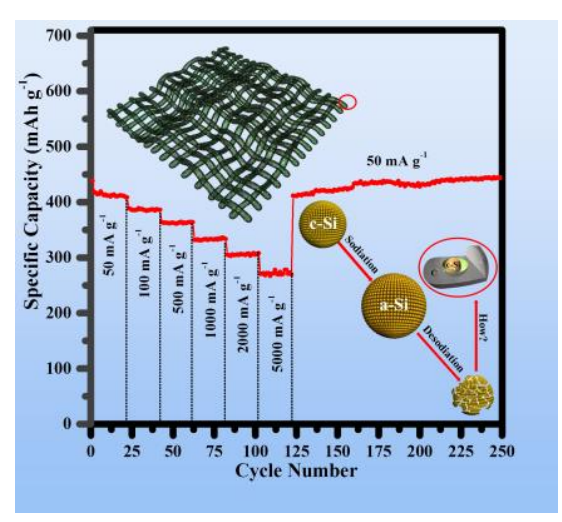


Copyright WILEY-VCH Verlag GmbH \& Co. KGaA, 69469 Weinheim, Germany, 2013.

\section{Supporting Information}

for Adv. Mater., DOI: 10.1002/adma.((please add manuscript number))

In-operando mechanism analysis on nanocrystalline silicon anode material for reversible and ultra-fast sodium storage

Lei Zhang, Xianluo Hu, * Chaoji Chen, Haipeng Guo, Xiaoxiao Liu, Gengzhao Xu, Haijian Zhong, Shuang Cheng, Peng Wu, Jiashen Meng, Yunhui Huang, * Shixue Dou, Huakun Liu* 


\section{Submitted to \\ ADVANCED}

(a)

(a)

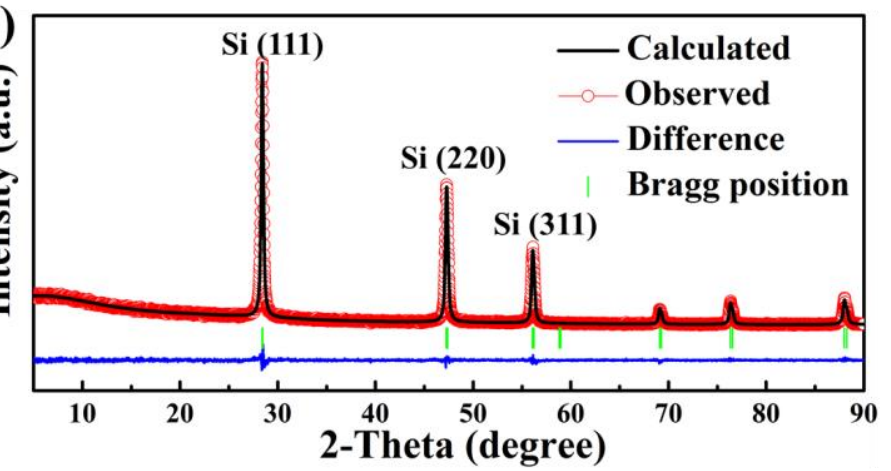

(c)

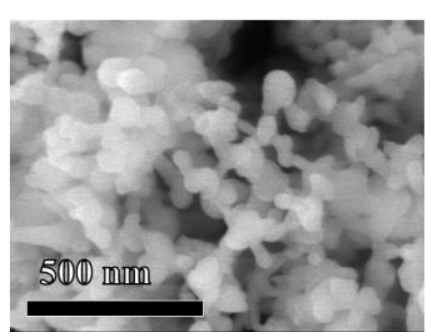

(d)

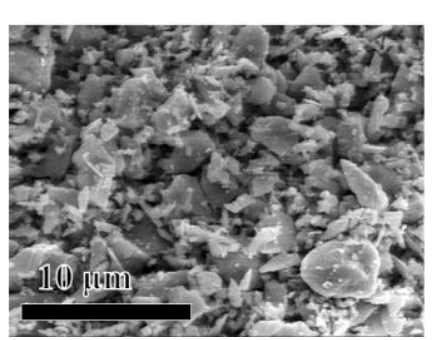

(b)

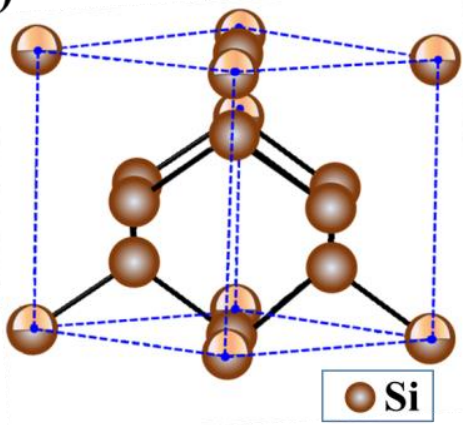

(e)

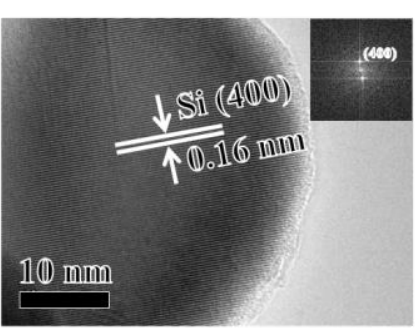

Figure S1. Morphology and structure of c-Si-based electrodes. (a) XRD patterns of nanosized c-Si with Rietveld refinement, (b) Schematics of the diamond cubic structure of nanosized c-Si, (c) SEM image of nanosized c-Si, (d) SEM image of microsized c-Si, and (e) the corresponding FFT pattern of HRTEM image of nanosized c-Si. 


\section{Submitted to
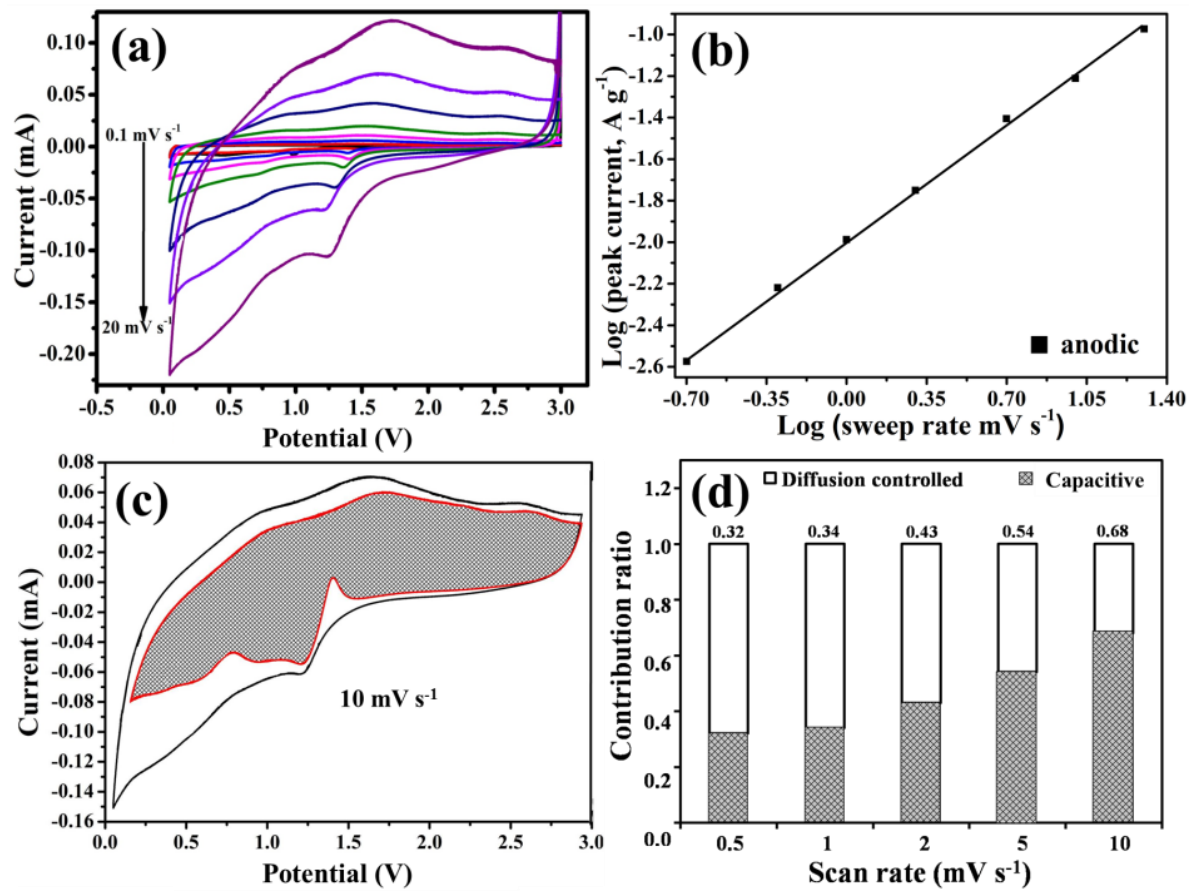

Figure S2. CV and Kinetics analysis of the electrochemical behavior towards $\mathrm{Na}^{+}$for the nanosized c-Si electrode. (a) CV curves of nanosized c-Si-based SIB at various scan rates, from 0.1 to $20 \mathrm{mV} \mathrm{s}^{-1}$, (b) determination of the b-value during the discharge processes using the relationship between peak current and scan rate, (c) separation of the capacitive and diffusion currents in nanosized c-Si at a scan rate of $10 \mathrm{mV} \mathrm{s}^{-1}$, and (d) contribution ratio of the capacitive and diffusion-controlled charge versus scan rate. 


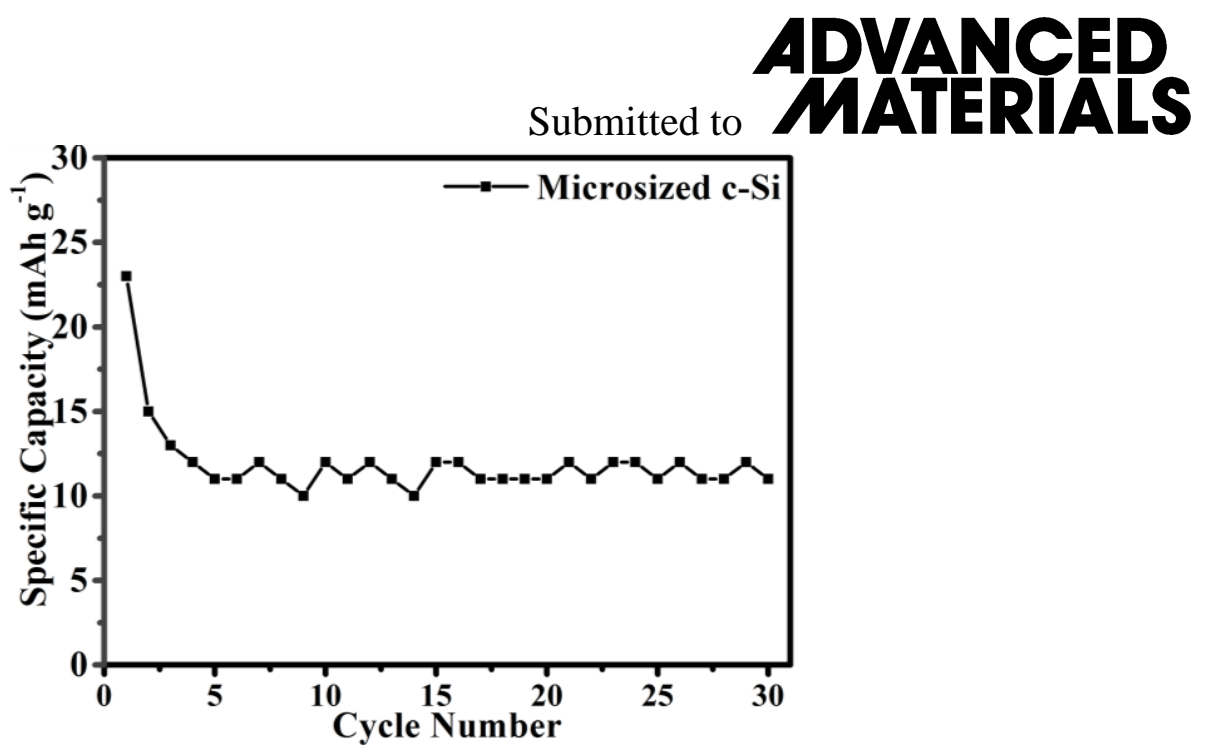

Figure S3. The discharge capacity of microsized c-Si at a current density of $50 \mathrm{~mA} \mathrm{~g}^{-1}$. 


\section{Submitted to

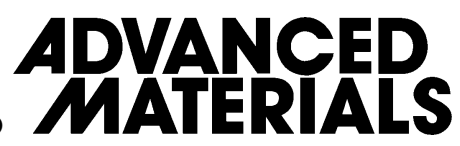

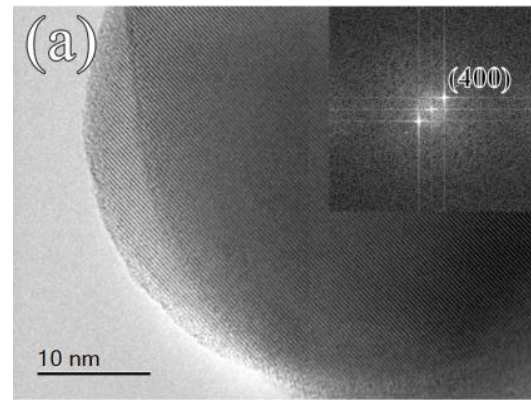

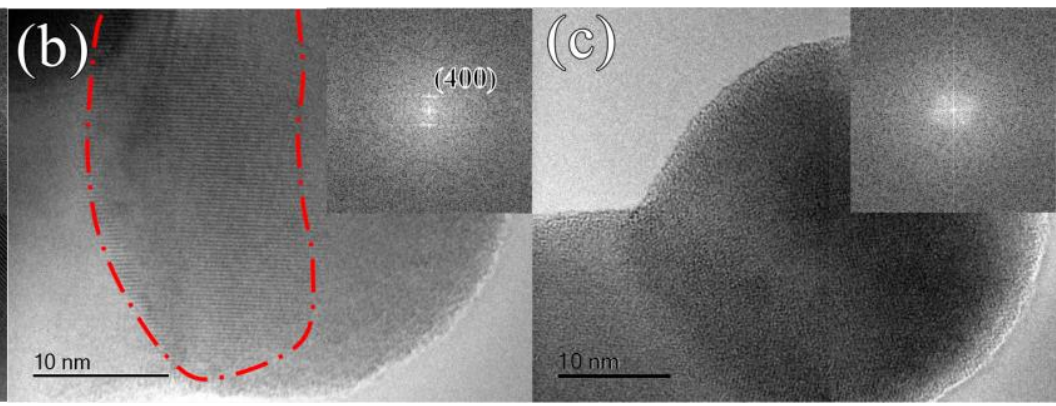

Figure S4. Morphology and structure characterization of the nanosized c-Si electrode under different electrochemical states. The corresponding FFT patterns of HRTEM images of nanosized c-Si before (a), after 1 cycle (b), and after 10 cycle test (c). 

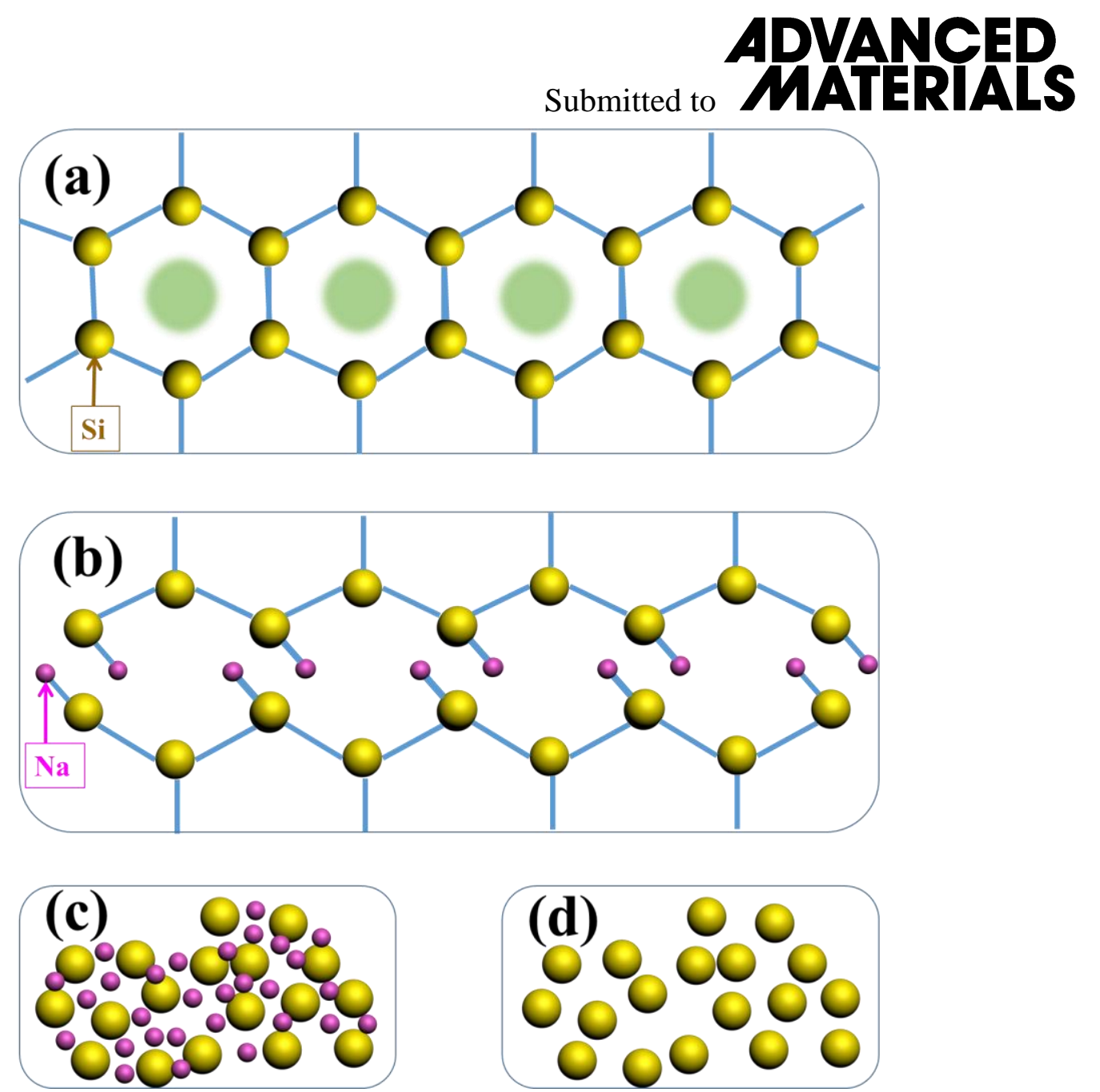

Figure S5. Schematic illustrations explaining the changes in the nanosized c-Si. (a) original c-Si, (b) $\mathrm{Si}-\mathrm{Si}$ bonds are broken and replaced by two Na-Si bonds in stable positions, (c) the propagation of $\mathrm{Si}-\mathrm{Si}$ bond breaking and sliding of $\mathrm{Na}$ atoms induce collapse of the planes, leading to an amorphous $\mathrm{Na}-\mathrm{Si}$ alloy, and (d) a-Si is obtained even after the desodiation process. (Red and yellow balls represent the interfacial $\mathrm{Na}$ and $\mathrm{Si}$ atoms, respectively) 


\section{Submitted to \\ ADVANCED}

Sodiation

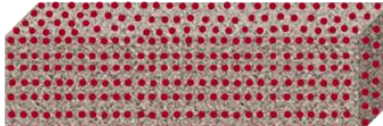

Desodiation

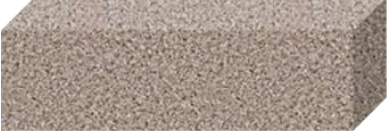

Microsized c-Si
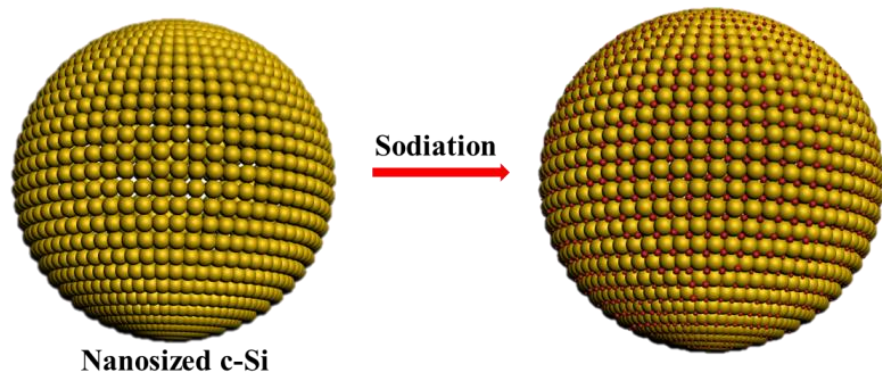

Desodiation

Nanosized c-S

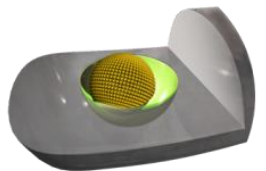

Sodiation

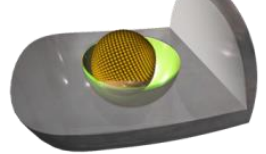

Desodiation

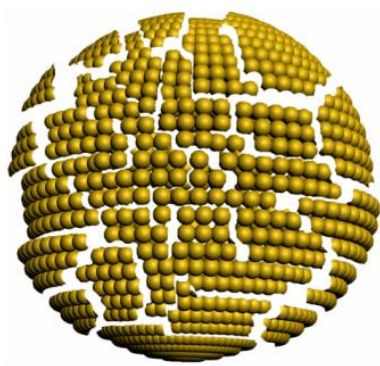

$\mathrm{Si} / \mathrm{C}$

Figure S6. The comparison among microsized c-Si, nanosized c-Si and the structure optimized $\mathrm{Si} / \mathrm{C}$ composite during the first sodiation/desodiation process. 


\section{ADVANCED \\ Submitted to MATERIALS}

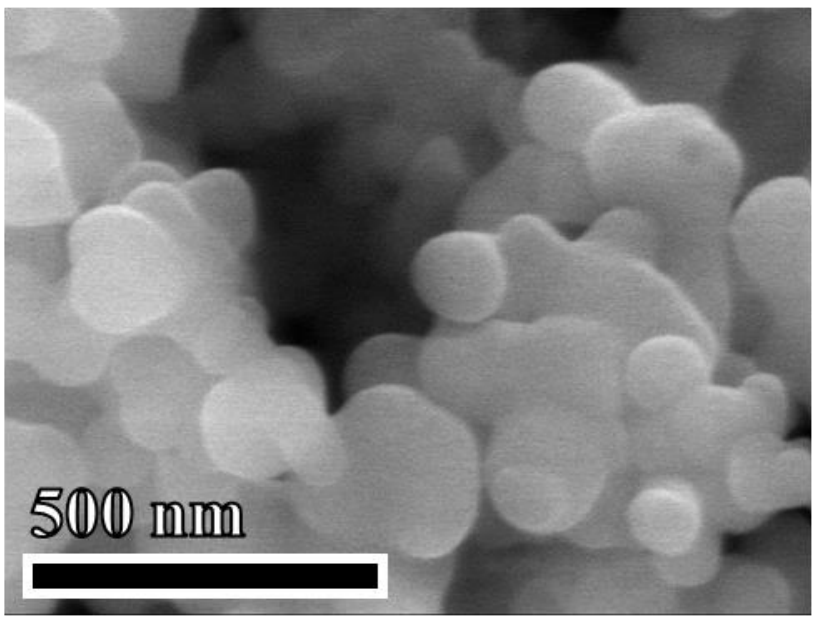

Figure S7. SEM image of $\mathrm{SiO}_{2} @ \mathrm{Si}$ 


\section{Submitted to \\ ADVANCED}
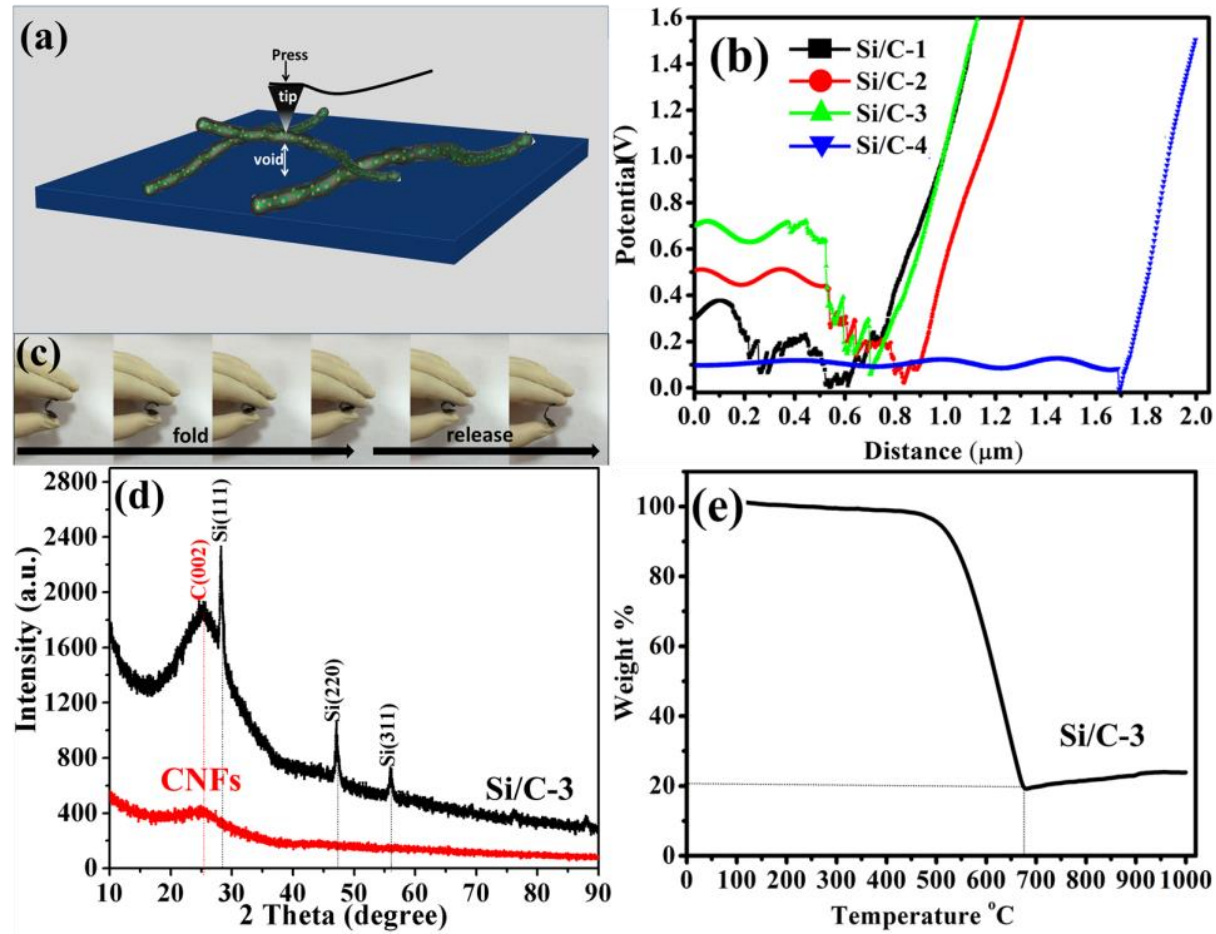

Figure S8. The model of the three-point bend test under AFM system (a), relationship between distance and voltage for the different samples (b), pictures of different states of a piece of Si/C-3 nanofiber web under fold and release process (c), the XRD profiles of the Si/C-3 sample and the pure CNFs (d), and TG curve of Si/C-3 under air (e). 
Submitted to

Table S1. Comparison of the presented alloy anode materials in SIBs.

\begin{tabular}{|c|c|c|}
\hline Category & Name & Reversible capacity $\left(\mathrm{mAh} \mathrm{g}^{-1}\right)$ \\
\hline \multirow{4}{*}{ Sb-based anodes } & Pure $\mathrm{Sb}$ & $660^{[1]}$ \\
\cline { 2 - 3 } & Amorphous AlSb & $\sim 400^{[2]}$ \\
\cline { 2 - 3 } & Amorphous $\mathrm{Mo}_{3} \mathrm{Sb}_{7}$ & $\sim 400^{[3]}$ \\
\cline { 2 - 3 } & $\mathrm{Sb} / \mathrm{C}$ & $640^{[4]}$ \\
\hline Sn-based anodes & $\mathrm{Pure} \mathrm{Sn}$ & $847^{[5]}$ \\
\hline & $\mathrm{Sn} / \mathrm{Ni}$ & $730^{[6]}$ \\
\hline & $\mathrm{Sn}_{0.9} \mathrm{Cu}_{0.1}$ & $420^{[7]}$ \\
\hline & $\mathrm{SnSb}$ & $500^{[8]}$ \\
\hline Ge-based anodes & Pure amorphous Ge & $400^{[9]}$ \\
\hline & $\mathrm{Ge}$ thin films & $<369^{[10]}$ \\
\hline In-based anodes & Pure In & $467^{[11]}$ \\
\hline & In thin film & $<100^{[11]}$ \\
\hline Si-based anodes & Pure c-Si & $960^{[12-13]}$ \\
\hline & $\mathrm{Si} / \mathrm{C}$ & 450 \\
\hline
\end{tabular}

[1] A. Darwiche, C. Marino, M. T. Sougrati, B. Fraisse, L. Stievano and L. Monconduit, J. Am. Chem. Soc. 2012, 134, 20805-20811.

[2] L. Baggetto, M. Marszewski, J. Gorka, M. Jaroniec and G. M. Veith, J. Power Sources. 2013, 243, 699-705.

[3] L. Baggetto, E. Allcorn, R. R. Unocic, A. Manthiram and G. M. Veith, J. Mater. Chem. A 2013, 1, 11163-1169.

[4] J. Qian, Y. Chen, L. Wu, Y. Cao, X. Ai and H. Yang, Chem. Commun. 2012, 48, 70707072.

[5] L. D. Ellis, T. D. Hatchard and M. N. Obrovac, J. Electrochem. Soc. 2012, 159, A1801A1805.

[6] Y. Liu, Y. Xu, Y. Zhu, J. N. Culver, C. A. Lundgren, K. Xu and C. Wang, ACS Nano 2013, 7, 3627-3634.

[7] Y.-M. Lin, P. R. Abel, A. Gupta, J. B. Goodenough, A. Heller and C. B. Mullins, ACS Appl. Mater. Interfaces 2013, 5, 8273-8277.

[8] L. Xiao, Y. Cao, J. Xiao, W. Wang, L. Kovarik, Z. Nie and J. Liu, Chem. Commun. 2012, 48, 3321-3323. 
[9] P. R. Abel, Y. Lin, T. de Souza, C. Chou, A. Gupta, J. B. Goodenough, G. S. Hwang,

A. Heller and C. B. Mullins, J. Phys. Chem. C 2013, 117, 18885-18890.

[10] L. Baggetto, J. K. Keum, J. F. Browning and G. M. Veith, Electrochem. Commun. 2013, 34, 41-44.

[11] S. A. Webb, L. Baggetto, C. A. Bridges and G. M. Veith, J. Power Sources 2014, 248, $1105-1117$.

[12] H. Moritoa, T. Yamada, T. Ikedab and H. Yamane, J. Alloys Compd. 2009, 480, 723726.

[13] T. Kume1, Y. Iwai, T. Sugiyama, F. Ohashi, T. Ban, S. Sasaki and S. Nonomura, Phys. Status Solidi C 2013, 10, 1739-1741. 


\section{ADVANCED
MATERIALS}

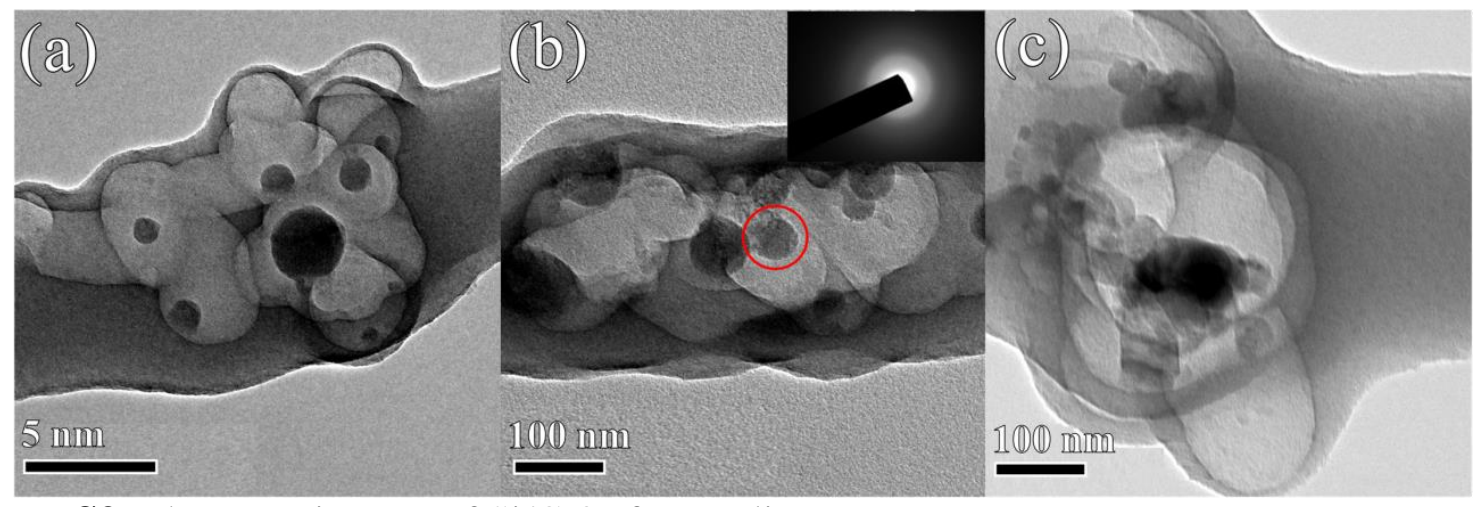

Figure S9. The TEM images of Si/C-3 after cycling test. 